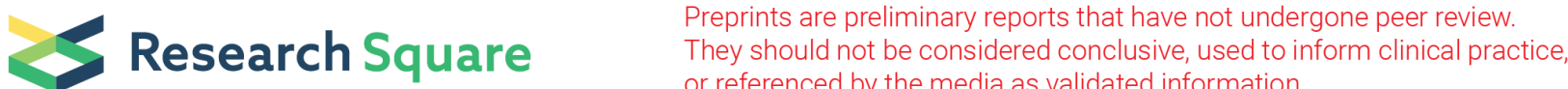 or referenced by the media as validated information.
}

\section{Confirmation of Rpp Genes Conferring Resistance to Asian Soybean Rust and Mapping of Rpp1 Allele from PI 594723}

\section{Daniela Meira}

Universidade Tecnologica Federal do Parana

\section{Vinícius de B. Bez Batti}

Universidade Tecnologica Federal do Parana

Leomar G. Woyann

Universidade Tecnologica Federal do Parana

Anderson Simionato Milioli

Universidade Tecnologica Federal do Parana

Antonio Henrique Bozi

Universidade Tecnologica Federal do Parana

Eduardo Beche

University of Missouri

Maiara Cecilia Panho

Universidade Tecnologica Federal do Parana

Fabiana Barrionuevo

Universidade Tecnologica Federal do Parana

Laura Alexandra Madella

Universidade Tecnologica Federal do Parana

\section{Gaspar Malone}

Universidade Federal de Pelotas

\section{Salvador L. Brito Júnior}

Universidade Federal do Parana

\section{Taciane Finatto}

Universidade Tecnologica Federal do Parana

Giovani Benin ( $\sim$ benin@utfpr.edu.br)

Agronomy College, Federal University for technology of Paraná, Pato Branco - PR, CEP 85501-970, Brazil. https://orcid.org/00000002-7354-5568

\section{Research Article}

Keywords: Phakopsora pachyrhizi, Rpp genes, Linkage mapping, KASP markers, Asian soybean rust (ASR), Glycine max

Posted Date: March 11th, 2021

DOI: https://doi.org/10.21203/rs.3.rs-267310/v1

License: @ (i) This work is licensed under a Creative Commons Attribution 4.0 International License. Read Full License 


\section{Abstract}

In this study, we aim to develop and validate KASP molecular markers in soybean populations for Asian soybean rust (ASR) resistance gene Rpp1 (PI 200492, PI 594538A, PI 587880A), identify the gene hypothetically present in PI 594723, and validate KASP markers for Rpp2 (PI 230970), Rpp3 (PI 506764), Rpp4 (PI 459025A), and Rpp5 (PI 506764, PI 200487). Ten $\mathrm{F}_{2}$ soybean (Glycine max (L.) Merrill) populations derived from crosses between rust-susceptible (55I57RSF IPRO, 63164RSF IPRO) x rust-resistant sources (PI 200492, PI 594738A, PI 587880A, PI 594723, PI 230970, PI 506764, PI 459025A and PI 200487) were evaluated. All F2 plants were individually evaluated in field conditions for ASR phenotypic reactions, classified according to sporulation level. SNP markers were developed according to markers associated with Rpp genes available at the SoyBase, using KASP methodology. Based on a slight difference in map position and different phenotypic disease reactions of PI 200492, the authors suggest that PI 594723 carries a resistance gene $R p p 1-b$. The Rpp1-b gene from PI 594723 was mapped in Chr 18 in a 12.4 cM region. The Pls carrying Rpp1-b (PI 594723, PI 587880A, and 594538A) showed strong resistance to ASR compared to the lines carrying Rpp1 (PI 200492). A total of $26 \mathrm{KASP}$ markers were significantly associated $(P<0.01)$ with ASR. Among those, M1, M5 and M6 (Rpp1), M13 and M14 (Rpp2), M16, M17 and M20 (Rpp3), M25 and M26 (Rpp4), and M27 and M28 (Rpp5) have the potential to be used in marker-assisted selection strategies.

\section{Introduction}

Asian soybean rust (ASR), caused by the biotrophic fungus Phakopsora pachyrhizi Syd. \& P. Syd, is considered one of the most damaging soybean (Glycine max (L.) Merrill) diseases worldwide (Langenbach et al. 2016; Godoy et al. 2016). Because of this pathogen dissemination and associated losses to soybean yield, there is a need for greater effort in researching ASR resistance (Meira et al. 2020). The pathogen can infect 31 leguminous species in natural conditions, such as G. max, G. soja, and Vigna unguiculata, and more than 60 different species in controlled conditions (Goellner et al. 2010).

P. pachyrhizi is present in main soybean producer regions, mainly because of the windborne urediniospores dispersion. When the urediniospores reach the leaf, ideal conditions of surface moisture and temperature ( 17 to $\left.28^{\circ} \mathrm{C}\right)$ initiate the germination process in a couple of hours. Most rust species enter the leaf through the stomata, but $P$. pachyrhizi direct penetrates the leaf epidermal cell wall by appressorial peg. After the latent period of five to eight days, small chlorotic spots on older leaves are observed on the abaxial side. These lesions advance to volcano-shaped uredina, which produce innumerous urediniospores responsible for the new infection cycle (Goellner et al. 2010). ASR causes early defoliation and reduces photosynthetic area, resulting in yield losses and increased costs (Langenbach et al. 2016; Godoy et al. 2016).

Several methods have been developed to control ASR, such as field monitoring, elimination of secondary hosts, use of soybean-free periods to break the fungus cycle, fungicides, and genetic resistance (Kendrick et al. 2011). In the last years, fungicide efficiency has decreased due to the intense use and lower pathogen sensitivity to different fungicide classes (Goellner et al. 2010; Langenbach et al. 2016). Thus, soybean breeders and geneticists have focused on incorporating genetic resistance or tolerance in high yielding materials, aiming to combine different control methods through an integrated management approach.

The Rpp genes confer hypersensibility reactions to the pathogen known as reddish brown (RB) lesions (Miles et al. 2011). The hypersensitive response occurs when the plant detects microbial effectors by plant resistance proteins $(R)$, elicits effector-triggered immunity, and promotes localized cell death (Boller and Felix 2009). Until now, seven different loci of qualitative resistance have been identified: Rpp1 on the chromosome (Chr) 18 (Hyten et al. 2007); Rpp2 on Chr 16 (Yu et al. 2015); Rpp3 on Chr 6 (Bromfield and Melching 1982); Rpp4 on Chr 18 (Hartwig 1986); Rpp5 on Chr 3 (Garcia et al. 2008); Rpp6 on Chr 18 (Li et al. 2012); and recently Rpp7 on Chr 19 (Childs et al. 2018), and two different alleles of Rpp1 were described, Rpp1-b (Chen et al. 2015; Chakraborty et al. 2009a) and Rpp1? (Ray et al. 2009).

Long-term resistance is difficult to achieve due to the diversity of pathogen isolates and race-specific monogenic resistance of each $R p p$ gene against ASR isolates (Aoyagi et al. 2020). The same resistance source may present different phenotypic reactions according to the geographic origin of the isolate. In general, the Brazilian ASR isolates are known as the most aggressive. The Rpp1 (PI 200492) is highly resistant to Japanese and Mexican ASR isolates, but a lack of resistance has been reported to Brazilian ASR isolates (Aoyagi et al. 2020; Akamatsu et al. 2017; Hossain et al. 2015). In contrast, the Rpp1-b (PI 587880A, PI 594538A) is resistant to most Brazilian ASR isolates (Ray et al. 2009; Yamanaka et al. 2016; Akamatsu et al. 2017), highlighting a clear allelic difference between Rpp1 and Rpp1-b. Moreover, the PI 594723 hypothetically present Rpp1-b because of the phenotype similarity to Pls carrying Rpp1-b (Li, 2009). Miles et al. (2008) reported high resistance of PI 594723 against Paraguayan ASR isolates. 
Introgression of resistance genes from plant introductions (PIs) in elite lines is an efficient way to release varieties with resistance to ASR. Marker-assisted selection (MAS) may guarantee selection in early generations, reducing phenotyping time and selecting only plants with the desirable allele combination. Single nucleotide polymorphism (SNP) markers are considered the best choice among contemporary breeding programs, mainly due to high throughput and low cost. In this way, a genotyping strategy using KASP (Kompetitive Allele-Specific PCR) methodology, a variant of PCR and based on allele-specific oligo extension, is a high-throughput and breeder-friendly fluorescence-based genotyping platform for SNP markers. KASP offers scalable flexibility in applications that require small to moderate numbers of markers. In soybean, the KASP technique has been successfully used to map Rpp7 from PI 605823 in Chr 19 (Childs et al. 2018).

In this study, we aim to develop and validate KASP molecular markers in soybean populations for ASR resistance gene Rpp 1 (PI, 200492, PI 594538A, PI 587880A), identify the gene hypothetically present in PI 594723, and validated KASP markers for Rpp2 (PI 230970), Rpp3 (PI 506764), Rpp4 (PI 459025A), and Rpp5 (PI 506764, PI 200487) resistance genes to Phakopsora pachyrhizi.

\section{Material And Methods}

\section{Plant material}

Ten $\mathrm{F}_{2}$ populations derived from single crosses between different soybean rust-susceptible cultivars and the resistant sources (PIs) carrying Rpp genes were developed (Table 1). The susceptible parental used in the crosses were highly cultivated genotypes in Brazil and contained the RR2BT trait. Crosses were performed in two phases, in 2017 for populations 1 to 4 and 2018 for populations 5 to 10 . The resistant sources (PIs) were used as male, and the susceptible soybean cultivars as female. $F_{1}$ hybrids were grown in greenhouse conditions, and bulk harvested for the $F_{2}$ generation were performed.

Table 1

Crosses between the soybean rust-susceptible parental and resistant sources (PI) and crop season of field experiments

\begin{tabular}{|c|c|c|c|c|c|}
\hline Population & Crop Season & $\begin{array}{l}\text { Susceptible } \\
\text { parental }\end{array}$ & Resistance source (PI number) - Rpp & $\mathrm{Chr}$ & Origin 9 \\
\hline $1-R p p 1$ & $2017 / 18$ & 55I57RSF IPRO & Komata (PI 200492) - Rpp $1^{1}$ & 18 & Japan \\
\hline $2-R p p 1-b$ & $2017 / 18$ & 55I57RSF IPRO & $(\mathrm{PI} 594538 \mathrm{~A})-R p p 1-b^{2}$ & 18 & China \\
\hline $3-R p p 1-b$ & $2017 / 18$ & 55I57RSF IPRO & Huang Dou (PI 587880A) - Rpp1- $b^{3}$ & 18 & China \\
\hline $4-R p p 1 *$ & $2017 / 18$ & 55I57RSF IPRO & He xian hei dou (PI 594723) - Rpp $1 * 4$ & 18 & China \\
\hline $5-R p p 1^{*}$ & $2018 / 19$ & 63I64RSF IPRO & He xian hei dou (PI 594723) - Rpp ${ }^{* 4}$ & 18 & China \\
\hline $6-R p p 2$ & $2018 / 19$ & 55I57RSF IPRO & PI $230970-R p p 2^{5}$ & 16 & Japan \\
\hline $7-R p p 3,5$ & $2018 / 19$ & 55I57RSF IPRO & Hyuuga (PI 506764) - Rpp3, Rpp5 & 6,3 & Japan \\
\hline $8-R p p 4$ & $2018 / 19$ & 55I57RSF IPRO & Bing nan (PI 459025A) - Rpp4 ${ }^{7}$ & 18 & China \\
\hline $9-R p p 5$ & $2018 / 19$ & 55I57RSF IPRO & Kinoshita (PI 200487) - Rpp $5^{8}$ & 3 & Japan \\
\hline $10-\operatorname{Rpp5}$ & $2018 / 19$ & 63I64RSF IPRO & Kinoshita (PI 200487) - Rpp $5^{8}$ & 3 & Japan \\
\hline
\end{tabular}

${ }^{1}$ PI 200492 - Hyten et al. (2007). ${ }^{2}$ PI 594538A - Chakraborty et al. (2009). ${ }^{3}$ PI 587880A- Ray et al. (2009).

${ }^{4} \mathrm{PI} 594723$ - Miles et al. (2006); ${ }^{5} \mathrm{PI} 230970$ - Hartwig and Bromfield (1983); ${ }^{6} \mathrm{PI} 506764$ - Kendrick et al. (2011); ${ }^{7} \mathrm{PI} 459025 \mathrm{~A}-$ Hartwig (1986); ${ }^{8} \mathrm{PI} 200487$ - Garcia et al. (2008); ${ }^{9} \mathrm{GRIN}$ - Germplasm Resources Information Network. Natl. Germplasm Resource. https://www.ars-grin.gov/

*PI 594723 carrying an Rpp1 allele not mapped until this moment.

The field experiments were designed to evaluate all the $F_{2}$ populations and were performed in two phases. First, during the 2017/18 crop season, $\mathrm{F}_{2}$ plants of populations 1 - Rpp1 (54 individuals), 2 - Rpp1-b (75 individuals), 3 - Rpp 1-b (70 individuals), and 4 - Rpp 1* (69 
individuals) were grown. During the 2018/19 crop season, $\mathrm{F}_{2}$ plants of populations 5 - Rpp1* (298 individuals), 6 - Rpp2 (277 individuals), 7 - Rpp3, 5 (288 individuals), 8 - Rpp4 (291 individuals), 9 - Rpp5 (284 individuals), and 10 - Rpp5 (284 individuals) were grown (Table 2). All $F_{2}$ plants were evaluated individually, totaling 1990 individuals (Table 3) used to disease rating, and 50 plants from each resistant and susceptible parent were rated. The experiments were planted on a non-preferential date (December) to enable the natural occurrence and development of Asian soybean rust, and no fungicide application was made to control the disease.

Table 2

Resistance loci to Asian soybean rust (ASR) mapped with molecular markers available at the SoyBase (https://www.soybase.org).

\begin{tabular}{|c|c|c|c|c|c|c|}
\hline PI & $R p p$ & Chr & $\begin{array}{l}\text { Marker } \\
\text { (start - end) }\end{array}$ & & $\begin{array}{l}\text { Distance } \\
\text { (kb) }\end{array}$ & Reference \\
\hline PI 200492 & Rpp1 & 18 & Sat_187 & Sat_064 & 152.1 & Hyten et al. 2007 \\
\hline PI 594538A & $R p p 1-b$ & 18 & Sat_064 & Sat_372 & 463.5 & Chakraborty et al. 2009 \\
\hline PI 587880A & Rpp1-b & 18 & Sat_064 & Satt191 & 1882.1 & Ray et al. 2009 \\
\hline PI 594723 & $R p p 1 *$ & 18 & - & - & - & - \\
\hline PI 230970 & Rpp2 & 16 & BARCSOYSSR_16_0902 & BARCSOYSSR_16_0908 & 188.1 & Yu et al. 2015 \\
\hline \multirow[t]{2}{*}{ PI 506764} & Rpp3, & 6 & satt460, & Satt307, & 2770.9 & Monteros et al. 2007; \\
\hline & Rpp5 & 3 & Satt275 & Sat_280 & 2808.1 & Kendrick et al. 2011 \\
\hline PI 459025A & Rpp4 & 18 & Satt288 & Af162283 & 6309.4 & Silva et al. 2008 \\
\hline PI 200487 & Rpp5 & 3 & Satt275 & Sat_280 & 2808.1 & Lemos et al. 2011 \\
\hline
\end{tabular}

Table 3

Segregation ratios of phenotypic reaction to Asian soybean rust (ASR) in $\mathrm{F}_{2}$ soybean populations

\begin{tabular}{|c|c|c|c|c|c|c|}
\hline \multirow[t]{2}{*}{ Pop - Rpp gene } & \multirow[t]{2}{*}{ Crossing } & \multicolumn{3}{|c|}{ Number of plants } & \multirow{2}{*}{$\begin{array}{l}\chi^{2} \\
\text { R:S (3:1) }\end{array}$} & \multirow{2}{*}{$\begin{array}{l}\chi^{2} \\
p(<0.05)\end{array}$} \\
\hline & & $\mathbf{R}$ & S & Total & & \\
\hline $\mathrm{P} 1-R p p 1$ & 55I57RSF IPRO x PI 200492 & 27 & 27 & 54 & 6.75 & 0.00 \\
\hline P2 - Rpp1-b & 55I57RSF IPRO x PI 594538A & 59 & 16 & 75 & 0.20 & 0.46 \\
\hline P3 - Rpp1-b & 55I57RSF IPRO x PI 587880A & 55 & 15 & 70 & 0.18 & 0.49 \\
\hline $\mathrm{P} 4-R p p 1 *$ & 55I57RSF IPRO x PI 594723 & 54 & 15 & 69 & 0.15 & 0.53 \\
\hline P5 - Rpp 1* & 63I64RSF IPRO x PI 594723 & 210 & 88 & 298 & 3.26 & 0.07 \\
\hline P6 - Rpp2 & 55I57RSF IPRO x PI 230970 & 172 & 105 & 277 & 24.61 & 0.00 \\
\hline P7 - Rpp3,5 & 55I57RSF IPRO x PI 506764 & 213 & 75 & 288 & $192.5^{1}$ & 0.00 \\
\hline P8 - Rpp4 & 55I57RSF IPRO x PI 459025A & 261 & 30 & 291 & 69.42 & 0.00 \\
\hline P9 - Rpp5 & 55I57RSF IPRO x PI 200487 & 226 & 58 & 284 & 3.17 & 0.07 \\
\hline P10 - Rpp5 & 63I64RSF IPRO x PI 200487 & 230 & 54 & 284 & 5.43 & 0.02 \\
\hline
\end{tabular}

\section{Resistance evaluation}

All $\mathrm{F}_{2}$ plants were evaluated for ASR phenotypic reactions in the R5 growth stage. Three infected leaves in the middle third of each plant were visually evaluated, according to a sporulation level (SL) scale adapted from Yamanaka et al. (2010) and Miles et al. (2011). Lesion types were recorded as immune (IM - 0), sporulation level of reddish-brown lesions (RB1-1), little sporulation (RB2-2), moderate sporulation (RB3-3), and reaction for abundant sporulation (TAN - 4) (Fig. 1). 


\section{KASP markers}

The SNP markers used in this study were developed according to markers available at the SoyBase (https://www.soybase.org), linked with Rpp genes (Table 2). Seventeen KASP markers were used to map the Rpp1 gene in the first experiment (Table S1). KASP markers highly associated with Rpp1 in PI 594723 and markers developed for Rpp2, Rpp3, Rpp4, and Rpp5 were used in the second experiment (Table S2). All consist of SNP markers developed using the KASP methodology (http://www.lgcgroup.com).

\section{DNA analysis}

DNA was extracted from young leaf tissue of each $F_{2}$ plant at the V4 growth stage, using a silica column kit of LGC Genomics (Teddington, UK). Genotyping assays were tested in a 96-well format and set up as $10 \mu \mathrm{L}$ reactions ( $4.85 \mu \mathrm{L}$ of template $(50-75 \mathrm{ng}$ of DNA), $5.0 \mu \mathrm{L}$ of $2 \times$ Kaspar mix, and $0.15 \mu \mathrm{L}$ of primer mix). PCR was performed according to the protocol: an initial $15 \mathrm{~min}$ at $94^{\circ} \mathrm{C} ; 10$ Touchdown cycles of $94^{\circ} \mathrm{C}$ for $20 \mathrm{~s}, 65-57^{\circ} \mathrm{C}$ for $60 \mathrm{~s}$ (dropping $0.8^{\circ} \mathrm{C}$ per cycle); 26 amplification cycles of $94^{\circ} \mathrm{C}$ for $20 \mathrm{~s}, 57^{\circ} \mathrm{C}$ for $60 \mathrm{~s}$; with final extension for $7 \mathrm{~min}$ at $72^{\circ} \mathrm{C}$. The fluorescence data were collected in the pre-read and post-read stages $\left(37^{\circ} \mathrm{C}\right.$ for $\left.1 \mathrm{~min}\right)$. Data were automatically processed using KBioscience Kraken software and visually checked using KBioscience SNPViewer (LGC Limited, UK).

\section{Statistical analysis}

Genotypic and phenotypic data of individual plants evaluated were analyzed. Observed and expected segregations ratios of ASR resistance and KASP markers were tested using Chi-square $\left(x^{2}\right)$ analysis. The expected segregations were 1:2:1 (dominant homozygous, heterozygous, and recessive homozygous) to markers, 3:1 (resistance and susceptible to ASR) to phenotype, and population 7 (Rpp3, 5) with two genes was 15:1. Phenotypic data were converted into resistant (R) summing IM, RB1, and RB2 plants; and as susceptible (S) summing the number of plants with RB3 and TAN lesions.

Linkage map analysis was performed to each mapping population (10 populations) using the MSTmap software (http://mstmap.org/mstmap_online.html), with Single LG to grouping LOD (logarithm of the odds), a threshold of $15 \mathrm{cM}$ to no mapping distance, and Kosambi mapping function to convert recombination values into map distances (cM). QTL mapping was performed using the composite interval mapping (CIM) functionality in the R package qtl (Broman et al. 2003). QTL positions for lesion type were defined as the peaks of maximum LOD score, and the significance thresholds were calculated by a 1000 permutation test analysis at $\mathrm{a} \leq 0.05$ significance level. QTL intervals were estimated via loading function, using 1.5-LOD support confident intervals. Single marker regression analysis was performed for each marker to test the significant association between markers and the ASR phenotypes and determine how much phenotypic variation could be explained for each KASP marker. Additive allelic effects were estimated by the substitution of resistant allele (AA) to susceptible allele (BB).

\section{Results}

Phenotype resistance

Most $\mathrm{F}_{2}$ soybean populations evaluated fit the expected segregation ratio of 3:1 (resistant: susceptible) for a dominant resistance gene (Table 3). Populations P1 - Rpp1, P6 - Rpp2, P8 - Rpp4, and P10 - Rpp5 did not fit the 3:1 ratio. Also, population 7 - Rpp3, 5 did not follow the expected segregation ratio for the two resistant gene model (15:1). These results can be associated with field conditions, where the populations were submitted to natural ASR infection, and more than one isolate could be present. The susceptible parents 55I57RSF IPRO and 63I64RSF IPRO produced TAN lesions, confirming the pathogen presence and their susceptibility (Fig. 2, Fig. 3).

Differences were observed in phenotypic response to ASR from Rpp1 sources (Fig. 1). PI 200492 (Rpp1, Chr 18) showed high susceptibility (RB3 lesions), and immune (IM) response was observed from PI 594538A (Rpp1-b, Chr 18) and PI 587880A (Rpp1-b, Chr 18). PI $594723\left(R p p 1^{*}\right)$ carrying unknow Rpp1 allele, not mapped until this moment, showed strong resistance to ASR, with RB1 lesion type.

Population 1 (P1 - Rpp1), with a total of 54 plants, presented $48 \%$ and $50 \%$ of plants RB3 and TAN, respectively (Fig. 2a). Therefore, segregation did not fit the expected segregation ratio of a single resistance gene (Table 3). P2 - Rpp 1-b and P3 - Rpp1-b, with the Rpp1 allele variation in resistance sources PI 594538A (Rpp1-b) and PI 587880A (Rpp1-b), respectively, fit in the expected phenotypic segregation, showing immunity (IM) reaction to ASR (Table 3). In P2 - Rpp 1-b, 28\% of the 75 plants showed an immune response to $P$. pachyrhizi, and in $\mathrm{P} 3,23 \%$ of 70 plants presented immune response (Fig. $2 \mathrm{~b}$ and $2 \mathrm{c}$ ). 
$\mathrm{PI} 594723\left(R p p 1^{*}\right)$ revealed strong resistance with reddish brown lesions and no visible sporulation (RB1). P4 - Rpp 1*and P5 - Rpp 1* fit the expected segregation ratio of a single resistance gene (Table 3). With a total of 69 and 298 plants, these populations showed $50.7 \%$ and $68.5 \%$ of the plants as RB1 and RB2, respectively (Fig. 2d, Fig. 3a).

The resistant parent of P6 - Rpp2 (PI 230970, Chr 16) showed a strong phenotypic reaction as RB1 lesions. P6 - Rpp2 with 277 plants presented $42 \%$ of the plants with RB2 lesions, and $17 \%$ and $32 \%$ of the plants showed RB1 and RB3 phenotypic reactions to ASR, respectively (Fig. 3b). PI 506764 carries Rpp3 (Chr 6) and Rpp5 (Chr 3) genes and presented an RB2 reaction to ASR (Fig. 3c). P7 - Rpp3, 5 has PI 506764 resistant genes and showed a weak resistance to ASR, with over $70 \%$ of 288 plants presenting RB2 or RB3 lesions.

Population P8 - Rpp4 showed weak resistance to ASR with 79\% of the plants with RB2 or RB3 lesions of 291 plants. This weak resistance to ASR is related to the disease reaction from the resistance source PI 459025A (Fig. 3d). P9 - Rpp5 and P10 - Rpp5, with 284 plants each population, carried the resistant allele Rpp5 (Chr 3) from PI 200487 and showed no sporulation lesion type (RB1) in only $14 \%$ of the plants, RB2 in 40\%, and RB3 in 25-29.6\% (Fig. 3e, 3f).

Mapping of resistance loci to ASR

Genotypic data revealed significant QTLs associated with the phenotypic reaction to ASR for all populations evaluated, except for P1 Rpp1 (Tables 4 and 5). In P1, no significant QTL was identified, and no markers showed significant association to phenotype reaction (Table S3). This result can be associated with weak resistance (RB3 lesion) of the parent carrying the Rpp1 gene on Chr 18 (PI 200492) (Fig. 2a), lack of phenotypic difference between homozygous resistant (AA) and homozygous susceptible (BB) genotypes (Table S3), or even related to the low number of markers used. The $F_{2}$ population showed a distorted segregation ratio that did not fit a ratio of $3: 1$ (Table 3). Aoyagi et al. (2020) and Akamatsu et al. (2017) reported the susceptibility of PI 200492 to ASR isolates from Brazil. 
Table 4

Summary of quantitative trait loci (QTL) for lesion type to Asian soybean rust (ASR) in ten $\mathrm{F}_{2}$ soybean populations.

\begin{tabular}{|c|c|c|c|c|c|c|c|c|c|c|c|c|}
\hline Populationa & Gene & Chr. ${ }^{b}$ & $\begin{array}{l}\text { Position } \\
\text { (cM) of } \\
\text { LOD } \\
\text { peak }\end{array}$ & $\begin{array}{l}\text { Flanking } \\
\text { Marker }\end{array}$ & $\begin{array}{l}\text { Marke } \\
\text { interve }\end{array}$ & & $\begin{array}{l}1.5 \\
\text { interval } \\
\text { (cM) }\end{array}$ & $\operatorname{LOD}^{d}$ & $p^{e}$ & $R^{2 f}$ & $\begin{array}{l}\text { Additive } \\
\text { effect }^{9}\end{array}$ & $\begin{array}{l}\text { Dominance } \\
\text { effect }^{9}\end{array}$ \\
\hline 1 & Rpp1 & 18 & -c & - & - & - & - & - & - & - & - & - \\
\hline 2 & $\begin{array}{l}\text { Rpp1- } \\
b\end{array}$ & 18 & 11.0 & M6 & M10 & M5 & $\begin{array}{l}7.3- \\
13.8\end{array}$ & 22.0 & $\begin{array}{l}< \\
0.001\end{array}$ & 68.3 & 1.77 & 0.40 \\
\hline 3 & $\begin{array}{l}\text { Rpp1- } \\
b\end{array}$ & 18 & 3.0 & M6 & M10 & M4 & $\begin{array}{l}0.0- \\
8.2\end{array}$ & 15.8 & $<0.001$ & 57.6 & 1.70 & 0.54 \\
\hline 4 & Rpp1* & 18 & 7.0 & M5 & M6 & M1 & $\begin{array}{l}2.7- \\
12.4\end{array}$ & 9.7 & $\begin{array}{l}< \\
0.001\end{array}$ & 42.2 & 0.80 & 0.48 \\
\hline 5 & Rpp1* & 18 & 2.1 & M6 & M6 & M1 & $\begin{array}{l}2.1- \\
9.8\end{array}$ & 20.9 & $\begin{array}{l}< \\
0.001\end{array}$ & 27.8 & 0.67 & 0.24 \\
\hline 6 & Rpp2 & 16 & 1.0 & M14 & M14 & M13 & $\begin{array}{l}0.3- \\
3.3\end{array}$ & 9.1 & $\begin{array}{l}< \\
0.001\end{array}$ & 14.1 & 0.42 & 0.35 \\
\hline \multirow[t]{2}{*}{7} & Rpp5 & 3 & 0.0 & M28 & M28 & M27 & $\begin{array}{l}0.0- \\
8.1\end{array}$ & 3.1 & $<001$ & 5.3 & 0.15 & -0.06 \\
\hline & Rpp3 & 6 & 13.0 & M17 & M20 & M16 & $\begin{array}{l}6.8- \\
15.9\end{array}$ & 7.2 & $\begin{array}{l}< \\
0.001\end{array}$ & 12.4 & 0.37 & -0.20 \\
\hline 8 & Rpp4 & 18 & 3.0 & M26 & M26 & M22 & $\begin{array}{l}3.0- \\
29.6\end{array}$ & 2.2 & 0.009 & 3.2 & 0.29 & -0.14 \\
\hline 9 & Rpp5 & 3 & 0.0 & M28 & M27 & M28 & $\begin{array}{l}0.0- \\
4.4\end{array}$ & 3.6 & $<.001$ & 5.8 & 0.44 & 0.08 \\
\hline 10 & Rpp5 & 3 & 0.7 & M27 & M27 & M28 & $\begin{array}{l}0.0- \\
0.7\end{array}$ & 4.1 & $<.001$ & 6.4 & 0.38 & 0.26 \\
\hline \multicolumn{13}{|c|}{ a Population, crosses between the soybean rust-susceptible parental and resistant sources, described on Table 1.} \\
\hline \multicolumn{13}{|c|}{ b Chr., Chromosome. } \\
\hline \multicolumn{13}{|c|}{${ }^{\mathrm{c}}$ There were no LOD peaks above the threshold to population $\mathrm{F}_{2}$. } \\
\hline \multicolumn{13}{|c|}{${ }^{\mathrm{d}} \mathrm{LOD}$, the logarithm of the odds. } \\
\hline \multicolumn{13}{|c|}{${ }^{\mathrm{e}} P$, probability of significance, calculated by single-factor analysis of variance. } \\
\hline \multicolumn{13}{|c|}{${ }^{f} R^{2}$, coefficient of determination calculated based on the nearest marker by regression analysis. } \\
\hline
\end{tabular}

P2 and P3, carrying Rpp1-b (Chr 18), presented a QTL in the same region with the LOD peak at marker M6, and an additive effect ranged from 1.70 and 1.77 (Table 4). The QTL explained $68.3 \%$ and $57.6 \%$ of the phenotypic reaction to ASR for P2 - Rpp 1-b and P3 - Rpp 1-b, respectively (Table S3). The resistance locus Rpp1-b in P2 was mapped between M5 and M10 (6.5 cM) and between M4 and M10 (8.2 CM) in P3 (Fig. S1). The Chi-square test revealed that all KASP markers mapped in P2 and P3 satisfactorily fitted the expected ratio for co-dominant inheritance (1:2:1) (Table S3).

PI 594723 presented strong resistance to ASR (Fig. 2d; Fig. 3a), and it is hypothesized that PI 594723 carries an unknown Rpp1* gene. A QTL was detected in P4 - Rpp1* between markers M1 and M6 on Chr 18 (Table 4). The QTL identified in P4 was validated in the P5 in the same region (M1 to M6). The QTLs explained $42.2 \%$ and $27.8 \%$ of the phenotypic variation for P4 and P5, respectively (Table S3, Fig. 4). The additive effects of this locus to increase susceptibility ranged from 0.67 to 0.80 . 
The Rpp2 gene was first mapped in PI 230970 on Chr 16 by Hartwig and Bromfield (1983). Yu et al. (2015) performed the fine mapping of this gene and defined the mapping in a physical interval of $188.1 \mathrm{~kb}$ on Chr 16. In P6 - Rpp2, the KASP markers used were developed based on the physical position of these markers. A QTL was identified on Chr 16 between markers M13 and M14 ( $3 \mathrm{cM}$ ), with the peak at M14 and explained $14.1 \%$ of the phenotypic variation for ASR resistance in the population (Table 4, Fig. S1). All markers were significantly associated with ASR (Table S3).

Population P7 carries two Rpp genes (Rpp3, Rpp5) from PI 506764. Rpp3 was mapped on Chr 6 between Satt307 and satt460 (Hyten et al. 2009), and Rpp5 on Chr 3 between Sat_275 and Sat_280 (Kendrick et al. 2011). The Rpp3 and Rpp5 genes were confirmed, and all KASP markers used were associated $(P \leq 0.002)$ with ASR (Tables 4 and 5). The Rpp5 gene was mapped between markers M28 and M27 on Chr 3 and explained 5.8\% of the phenotypic variation for ASR. Rpp3 was mapped on Chr 6 between markers M20 and M17 (Fig. S2) and explained $12.4 \%$ of the phenotypic response to ASR resistance.

Genotypic data revealed a significant QTL associated with ASR on Chr 18 between the markers M26 and M22 on P8 - Rpp4 (Table 4, Fig. S2), confirming the Rpp4 locus in the PI 459025A (Silva et al. 2008). M26 was associate $(P \leq 0.009)$ with ASR and explained $3.2 \%$ of the phenotypic variation for the trait (Table S3). Populations P9 and P10 have the Rpp5 from PI 200487. The Rpp5 locus was mapped between the markers M27 and M28 (Fig. S2) and explained 5.8-6.4\% of the phenotypic variation (Table 4 and Table S3). The additive effect for the QTL ranged from 0.38 to 0.44 , dependent on the population.

\section{Discussion}

Several factors could lead to inconsistent results in the segregation ratio of $F_{2}$ soybean populations evaluated in this study. The trials were conducted in field conditions, where the combination of different ASR isolates, natural infection and weather conditions could promote high inoculum pressure. In addition, the ASR isolates presented in Brazil are considered more virulent than ones found in Japan, Argentina, and Paraguay (Yamanaka et al. 2010; Aoyagi et al. 2020).

A comparison of ASR reactions of PI 594723 with other Pls carrying Rpp1 (PI 200492) and Rpp1-b (PI 594538A and PI 587880A) showed higher similarity to Rpp 1-b phenotypic response. The PI 594723 presented strong resistance, while the PI 200492 was classified as being weakly resistant (RB3 lesion type). Aoyagi et al. (2020) observed susceptibility of PI 200492 against Brazilian ASR. Therefore, the PI 587880A showed less sporulation to ASR isolates, corroborating the present study results. Aoyagi et al. (2020) reported clear differences in the ASR reactions from genotypes carrying Rpp1 and Rpp1-b, and also among sources of Rpp1 such as PI 587886, Himeshirazu, and PI 200492, showing infection reactions of susceptibility, high resistance, and immunity respectively to the same isolate. Hossain et al. (2015) and Akamatsu et al. (2017) corroborate these differences in reactions to different isolates between accessions with the Rpp 1 locus and genotypes with Rpp1-b.

The phenotypic reaction and mapping location suggested that PI 594723 carries the locus Rpp 1-b. Ray et al. (2009) identified the gene Rpp1-b on Chr 18 from PI 587880A in the same region we identified the Rpp1*locus on P4 and P5. In a few studies performed with this resistance source, Miles et al. (2008) reported resistant RB lesion type, with reduced sporulation level and low severity, in greenhouse and field conditions in Paraguay. However, Li (2009) observed moderate resistance of PI 594723 to Mississippi isolates.

Pedley et al. (2019) studying the source of resistance at the Rpp 1 locus (PI 200492), in the previous locus region mapped between markers Sct_187 and Sat_064 (Hyten et al. 2007) (Gm18: 56,182,230 to 56,333,803), identified a leucine-rich repeat (NBS-LRR) protein with a novel ubiquitin-like-specific protease 1 (ULP1) domain associated to the Rpp1. The NBS-LRR domain is usually associated with R proteins that detect the pathogen and start signaling pathways.

Regarding the eight R genes reported in the Rpp 1 locus, R1 and R2, R6 to R8 are located before and after the physical position of Rpp1, respectively (Pedley et al. 2019). This fact can explain the immunity, and hypersensibility reaction to ASR observed in this study to PI 587880A, PI 594538A, and PI 594723 carrying Rpp1-b (Fig. 1). Chakraborty et al. (2009) mapped Rpp1-b on PI 594538A between markers Sat_064 and Sat_372, which agree with the physical position of R6 to R8. The Rpp1-b mapped on PI 587880A was located between markers Sat_191 and Sat_187 (Ray et al. 2009), which is in the same physical position of R1 and R8 resistance genes. Thus, according to the mapping proposed of PI 594723, eight homologous to the NBS-LRR family of disease R genes could be present (Pedley et al. 2019).

The markers previously mapped to Rpp1-b in PI 594723 (M1, M6, and M11) were confirmed in the P5 - Rpp1-b. This population avoids pathogen infection through hypersensibility reactions, resulting in lesions without sporulation, known as RB1 (Fig. 1). This resistant 
source has great potential to be used in breeding for ASR resistance, especially in South America. The flanking and interval KASP marker used in these populations (P4 and P5 - Rpp1-b) allows it to select plants with strong resistance.

The PI 230970 carries the dominant gene Rpp2 (Hartwig and Bromfield, 1983; Silva et al. 2008). In addition, Yu et al. (2015) fine mapped Rpp2 from PI 230970 into a $188.1 \mathrm{~kb}$ region. Our results confirmed the Rpp2 gene from PI 230970 on Chr 16 . However, the phenotypic segregation ratio for P6 - Rpp2 did not follow the expected 3:1 ratio. A good explanation for that may be that multiple isolates could be presented in the area since we had a natural infestation. Garcia et al. (2008) observed a similar trend when they used a different ASR isolate than previously used by Bromfield \& Hartwig (1980) to map Rpp2 from PI 230970.

Despite PI 506764 natural gene pyramiding (Rpp3 and Rpp5), the phenotype reaction to ASR by P7 (Rpp3, 5) corroborates with results obtained by Walker et al. (2014). These authors described the PI 506764 as presenting a medium level of sporulation and RB lesions to ASR (Walker et al. 2011; Walker et al. 2014; Kendrick et al. 2011). Aoyagi et al. (2020) genotyped soybean landraces (WV51 and WC61) carrying Rpp3 and reported different phenotypic reactions to isolates, presenting slight resistance to Brazilian isolates, agreeing with our results. The Rpp5 (PI 200487), mapped in Chr 3 between markers Sat_275 and Sat_280 (Garcia et al. 2008) showed great potential to be used in breeding programs. Our results demonstrated the contribution of $R p p 5$ to increase levels of resistance in pyramided-lines contain Rpp3+Rpp5 (Fig. S3).

The resistant source carrying Rpp4 (PI 459025A) presented satisfactory resistance to ASR. According to Hossain \& Yamanaka (2019), this PI showed strong resistance against $80 \%$ of isolates from Bangladesh and Japan. However, when this source was submitted to South American isolates (Brazil, Argentina, and Paraguay), the PI 459025A showed resistance to 50\% of the isolates. Rpp4 and Rpp1 were mapped in the same linkage group on Chr 18, and this region is considered a hotspot for ASR resistance in soybean (Hyten et al. 2007; Silva et al. 2008). Previous studies with Rpp4 verified a biphasic response to ASR, proposing that the gene detect effectors in the haustoria developing stage due to one or more of the multiple TIR-NBS-LRR candidate genes in the region (Meyer et al. 2009). These authors support the hypothesis that susceptibility to ASR can be associated with small amino acid differences responsible for playing a key role in resistance.

Pyramiding resistant genes in a single line can confer more durable and broad-spectrum resistance to a pathogen. Yamanaka \& Hossain (2019) observed higher resistance to ASR when combined in one line multiple Rpp genes depending on the isolate. The KASP markers validated in this study might be used in MAS strategies to pyramiding different $R p p$ genes in one single line.

In conclusion, based on a slight difference in map position and a different reaction to ASR of PI 200492, the data suggested that PI 594723 carries a resistance gene Rpp1-b. The PIs carrying Rpp1-b (PI 594723, PI 587880A, and 594538A) showed strong resistance to ASR and generated high resistance plants when crossed with susceptible commercial cultivars. A total of $26 \mathrm{KASP}$ markers were significantly associated $(P<0.01)$ with ASR and successfully mapped the resistant loci $R p p 1, R p p 2, R p p 3$, Rpp4, and Rpp5. Among the 26, M1, M5, and M6 (Rpp1), M13 and M14 (Rpp2), M16, M17 and M20 (Rpp3), M25 and M26 (Rpp4), and M27 and M28 (Rpp5) have the potential to be used in marker-assisted selection strategies.

\section{Declarations}

\section{Authors' Contributions}

DM and VB conducted field evaluations and data analysis; MP, LM, FB and AB performed data collection and genotyping; DM, VB, LW, $A M, E B$ wrote the paper; GB, GM and SJ supervised the research; GB, GM, SJ, TF, EB revised and edited the manuscript. All authors read the manuscript.

\section{Acknowledgements}

To Coordenação de Aperfeiçoamento de Pessoal de Nível Superior (CAPES) for granting the masters and doctoral scholarships. We also thank GDM Seeds for providing funds and resources to support this project.

\section{Ethical Responsibilities}

The manuscript attends rules of the "Ethical Responsibilities of Authors":

- The manuscript is only submitted to Euphytica. 
- The submitted work is original and not have been published elsewhere in any form or language (partially or in full).

- The study was not split up into several parts to increase the quantity of submissions and submitted to various journals or to one journal over time.

- Results present clearly, honestly, and without fabrication, falsification or inappropriate data manipulation (including image based manipulation).

- No data, text, or theories by others are presented as if they were the author's own ('plagiarism').

- We have permissions for the use of software, questionnaires/(web) surveys and scales in our study.

- The Authors' information about an entity (who can be an individual person or a company) is true.

- Research is not a threat to public health or national security.

- The corresponding author ensures the author group and the order of authors are all correct at submission. There will not adding and/or deleting authors.

\section{DECLARATION OF COMPETING INTEREST}

The authors declare no conflict of interest.

\section{References}

Akamatsu H, Yamanaka N, Soares RM, et al (2017) Pathogenic variation of South American Phakopsora pachyrhizi populations isolated from Soybeans from 2010 to 2015. Japan Agric Res Q 51:221-232. https://doi.org/10.6090/jarq.51.221

Aoyagi LN, Muraki Y, Yamanaka N (2020) Characterization of three soybean landraces resistant to Asian soybean rust disease. Mol Breed 40:53. https://doi.org/10.1007/s11032-020-01132-w

Boller T, Felix G (2009) A Renaissance of Elicitors: Perception of Microbe-Associated Molecular Patterns and Danger Signals by PatternRecognition Receptors. Annu Rev Plant Biol 60:379-406. https://doi.org/10.1146/annurev.arplant.57.032905.105346

Broman KW, Wu H, Sen S, Churchill GA (2003) R/qtl: QTL mapping in experimental crosses. Bioinformatics 19:889-890. https://doi.org/10.1093/bioinformatics/btg112

Bromfield, K. R. \& Hartwig EE (1980) Resistance to soybean rust and mode of inheritance. Crop Sci 20:254-255

Bromfield KR, Melching JS (1982) Sources of specific resistance to soybean rust. Soybean Rust Newsl 5:3

Chakraborty N, Curley J, Frederick RD, et al (2009a) Mapping and Confirmation of a New Allele at Rpp1 from Soybean PI 594538A Conferring RB Lesion-Type Resistance to Soybean Rust. Crop Sci 49:783-790. https://doi.org/10.2135/cropsci2008.06.0335

Chakraborty N, Curley J, Frederick RD, et al (2009b) Mapping and confi rmation of a new allele at rpp1 from soybean pi 594538a conferring rb lesion-type resistance to soybean rust. Crop Sci 49:783-790. https://doi.org/10.2135/cropsci2008.06.0335

Chen H, Zhao S, Yang Z, et al (2015) Genetic analysis and molecular mapping of resistance gene to Phakopsora pachyrhizi in soybean germplasm SX6907. Theor Appl Genet 128:733-743. https://doi.org/10.1007/s00122-015-2468-2

Childs SP, King ZR, Walker DR, et al (2018) Discovery of a seventh Rpp soybean rust resistance locus in soybean accession PI 605823. Theor Appl Genet 131:27-41. https://doi.org/10.1007/s00122-017-2983-4

Garcia A, Calvo ÉS, de Souza Kiihl RA, et al (2008) Molecular mapping of soybean rust (Phakopsora pachyrhizi) resistance genes: discovery of a novel locus and alleles. Theor Appl Genet 117:545-553. https://doi.org/10.1007/s00122-008-0798-z

Goellner K, Loehrer M, Langenbach C, et al (2010) Phakopsora pachyrhizi, the causal agent of Asian soybean rust: Pathogen profile. Mol Plant Pathol 11:169-177. https://doi.org/10.1111/j.1364-3703.2009.00589.x

Hartwig EE (1986) Identification of a Fourth Major Gene Conferring Resistance to Soybean Rust 1. Crop Sci 26:1135-1136. https://doi.org/10.2135/cropsci1986.0011183X002600060010x 
Hartwig EE, Bromfield KR (1983) Relationships Among Three Genes Conferring Specific Resistance to Rust in Soybeans 1. Crop Sci 23:237-239. https://doi.org/10.2135/cropsci1983.0011183X002300020012x

Hossain MM, Akamatsu H, Morishita M, et al (2015) Molecular mapping of Asian soybean rust resistance in soybean landraces PI 594767A, PI 587905 and PI 416764. Plant Pathol 64:147-156. https://doi.org/10.1111/ppa.12226

Hossain MM, Yamanaka N (2019) Pathogenic variation of Asian soybean rust pathogen in Bangladesh. J Gen Plant Pathol 85:90-100. https://doi.org/10.1007/s10327-018-0825-0

Hyten DL, Hartman GL, Nelson RL, et al (2007) Map Location of the Rpp1 Locus That Confers Resistance to Soybean Rust in Soybean. Crop Sci 47:837-838. https://doi.org/10.2135/cropsci2006.07.0484

Hyten DL, Smith JR, Frederick RD, et al (2009) Bulked Segregant Analysis Using the GoldenGate Assay to Locate the Rpp3 Locus that Confers Resistance to Soybean Rust in Soybean. Crop Sci 49:265-271. https://doi.org/10.2135/cropsci2008.08.0511

Kendrick MD, Harris DK, Ha B-K, et al (2011) Identification of a Second Asian Soybean Rust Resistance Gene in Hyuuga Soybean. Phytopathology ${ }^{\circledR}$ 101:535-543. https://doi.org/10.1094/PHYTO-09-10-0257

Langenbach C, Campe R, Beyer SF, et al (2016) Fighting Asian Soybean Rust. Front Plant Sci 7:.

https://doi.org/10.3389/fpls.2016.00797

Li S (2009) Reaction of soybean rust-resistant lines identifi ed in paraguay to mississippi isolates of Phakopsora pachyrhizi. Crop Sci 49:887-894. https://doi.org/10.2135/cropsci2008.06.0305

Li S, Smith JR, Ray JD, Frederick RD (2012) Identification of a new soybean rust resistance gene in PI 567102B. Theor Appl Genet 125:133-142. https://doi.org/10.1007/s00122-012-1821-y

Meira D, Woyann LG, Bozi AH, et al (2020) Asian soybean rust: a scientometric approach of Phakopsora pachyrhizi studies. Euphytica 216:133. https://doi.org/10.1007/s10681-020-02667-x

Meyer JDF, Silva DCG, Yang C, et al (2009) Identification and Analyses of Candidate Genes for Rpp4-Mediated Resistance to Asian Soybean. 150:295-307. https://doi.org/10.1104/pp.108.134551

Miles MR, Bonde MR, Nester SE, et al (2011) Characterizing Resistance to Phakopsora pachyrhizi in Soybean. Plant Dis 95:577-581. https://doi.org/10.1094/PDIS-06-10-0450

Miles MR, Morel W, Ray JD, et al (2008) Adult Plant Evaluation of Soybean Accessions for Resistance to Phakopsora pachyrhizi in the Field and Greenhouse in Paraguay. Plant Dis 92:96-105. https://doi.org/10.1094/PDIS-92-1-0096

Pedley KF, Pandey AK, Ruck A, et al (2019) Rpp1 Encodes a ULP1-NBS-LRR Protein That Controls Immunity to Phakopsora pachyrhizi in Soybean. Mol Plant-Microbe Interact 32:120-133. https://doi.org/10.1094/MPMI-07-18-0198-FI

Ray JD, Morel W, Smith JR, et al (2009) Genetics and mapping of adult plant rust resistance in soybean PI 587886 and PI $587880 \mathrm{~A}$. Theor Appl Genet 119:271-280. https://doi.org/10.1007/s00122-009-1036-z

Silva DCG, Yamanaka N, Brogin RL, et al (2008) Molecular mapping of two loci that confer resistance to Asian rust in soybean. Theor Appl Genet 117:57-63. https://doi.org/10.1007/s00122-008-0752-0

Walker DR, Boerma HR, Phillips D V. et al (2011) Evaluation of USDA Soybean Germplasm Accessions for Resistance to Soybean Rust in the Southern United States. Crop Sci 51:678-693. https://doi.org/10.2135/cropsci2010.06.0340

Walker DR, Harris DK, King ZR, et al (2014) Evaluation of Soybean Germplasm Accessions for Resistance to Phakopsora pachyrhizi Populations in the Southeastern United States, 2009-2012. Crop Sci 54:1673-1689. https://doi.org/10.2135/cropsci2013.08.0513

Yamanaka N, Hossain MM (2019) Pyramiding three rust-resistance genes confers a high level of resistance in soybean ( Glycine max ). Plant Breed 138:686-695. https://doi.org/10.1111/pbr.12720 
Yamanaka N, Morishita M, Mori T, et al (2016) The locus for resistance to Asian soybean rust in PI 587855. Plant Breed 135:621-626. https://doi.org/10.1111/pbr.12392

Yamanaka N, Yamaoka Y, Kato M, et al (2010) Development of classification criteria for resistance to soybean rust and differences in virulence among Japanese and Brazilian rust populations. Trop Plant Pathol 35:153-162. https://doi.org/10.1590/S1982-

56762010000300003

Yu N, Kim M, King ZR, et al (2015) Fine mapping of the Asian soybean rust resistance gene Rpp2 from soybean PI 230970. Theor Appl Genet 128:387-396. https://doi.org/10.1007/s00122-014-2438-0

\section{Figures}

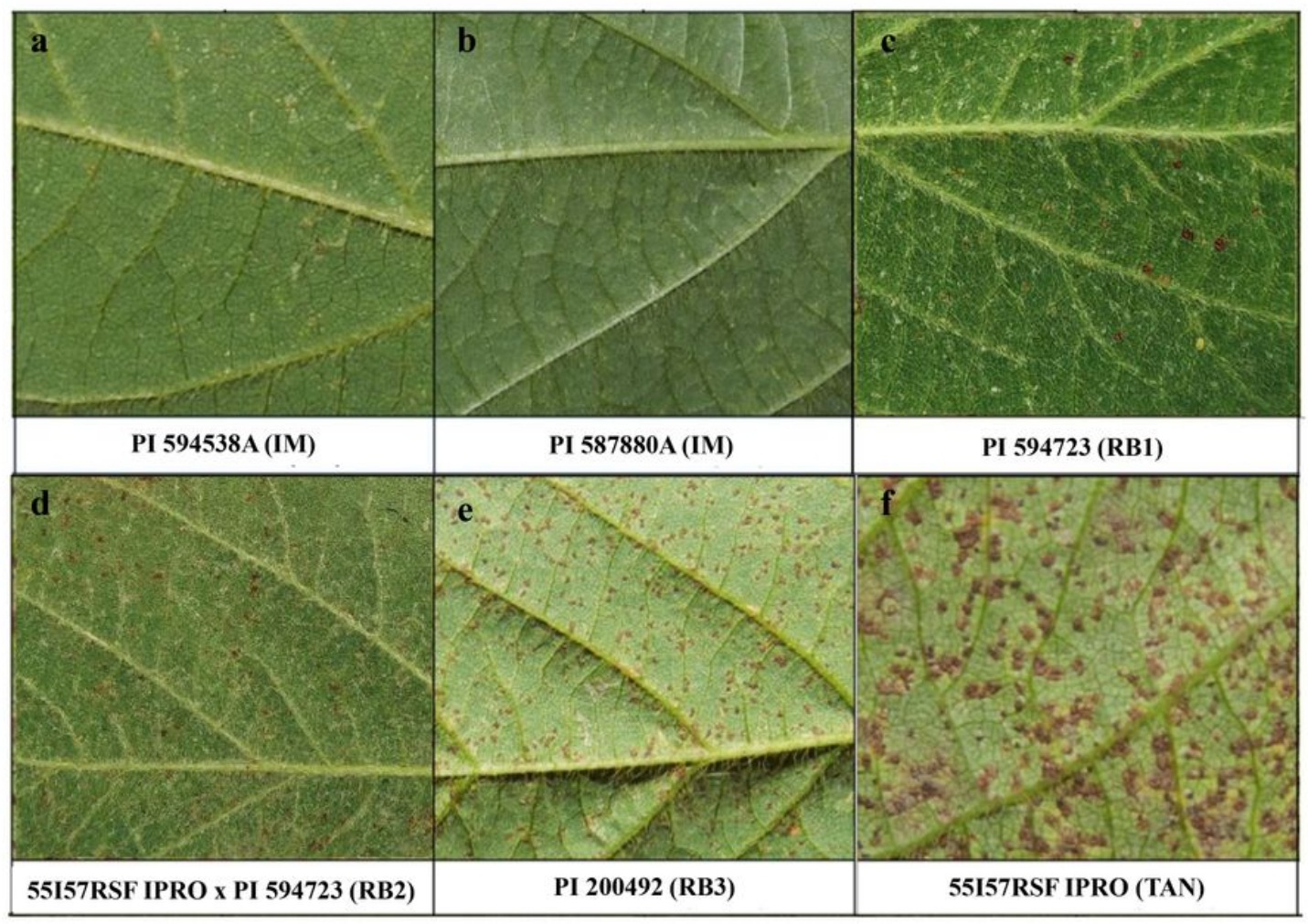

\section{Figure 1}

Phenotypic reaction to Phakopsora pachyrhizi in soybean genotypes and F2 populations. a) PI 594538A (Rpp1-b), b) PI 587880A (Rpp1b), c) PI 594723 (Rpp1), d) 55i57RSF IPRO x PI 594723, e) PI 200492 (Rpp1), and f) 55i57RSF IPRO 

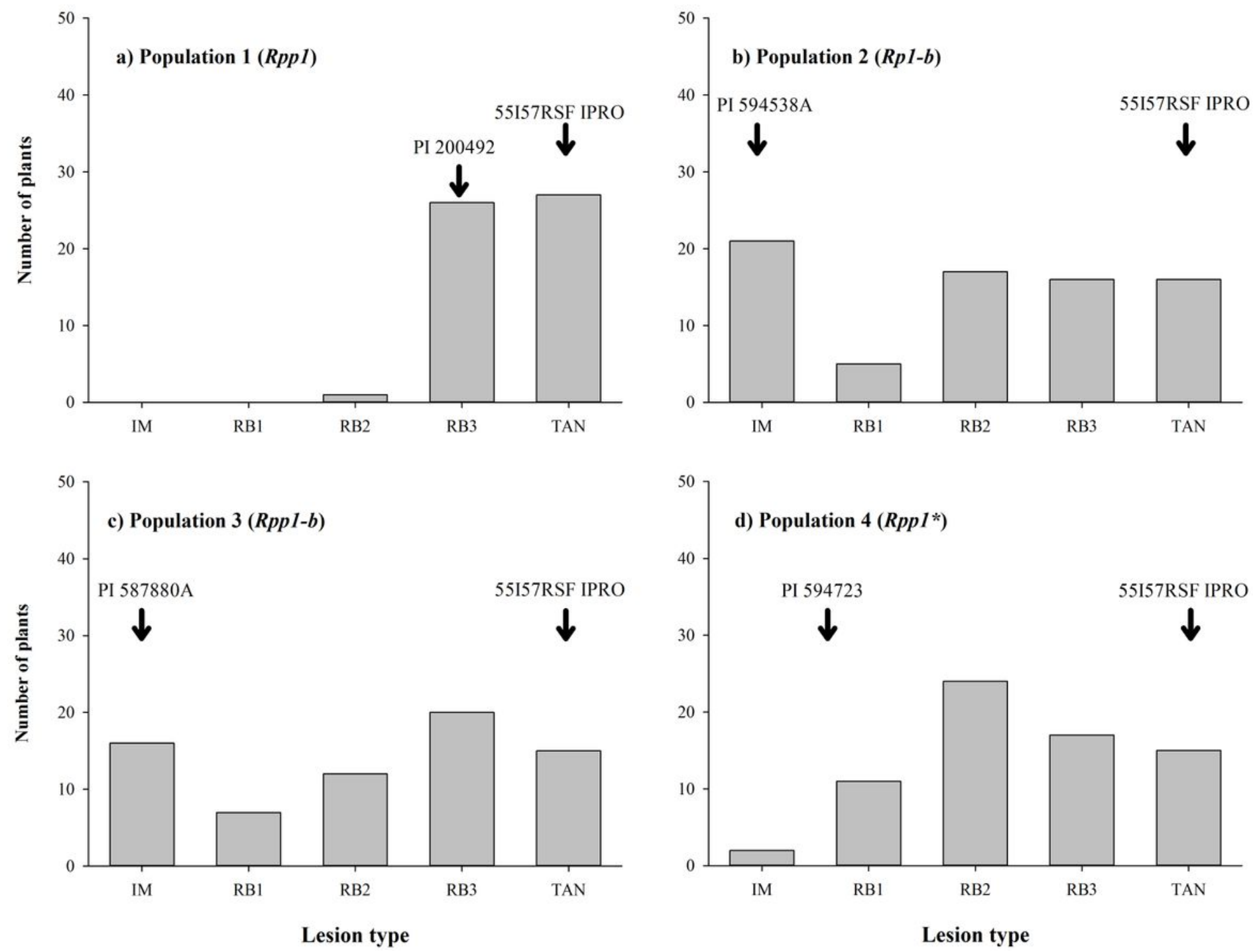

Figure 2

Frequency distributions of phenotypic reaction to Asian soybean rust (ASR) in F2 soybean populations. a) Population 1 - Rpp1 (55I57RSF IPRO x PI 200492. b) Population 2 - Rpp1-b (55I57RSF IPRO x PI 594538A. c) Population 3 - Rpp1-b (55I57RSF IPRO x PI 587880A). d) Population 4 - Rpp1* (55I57RSF IPRO x PI 594723 

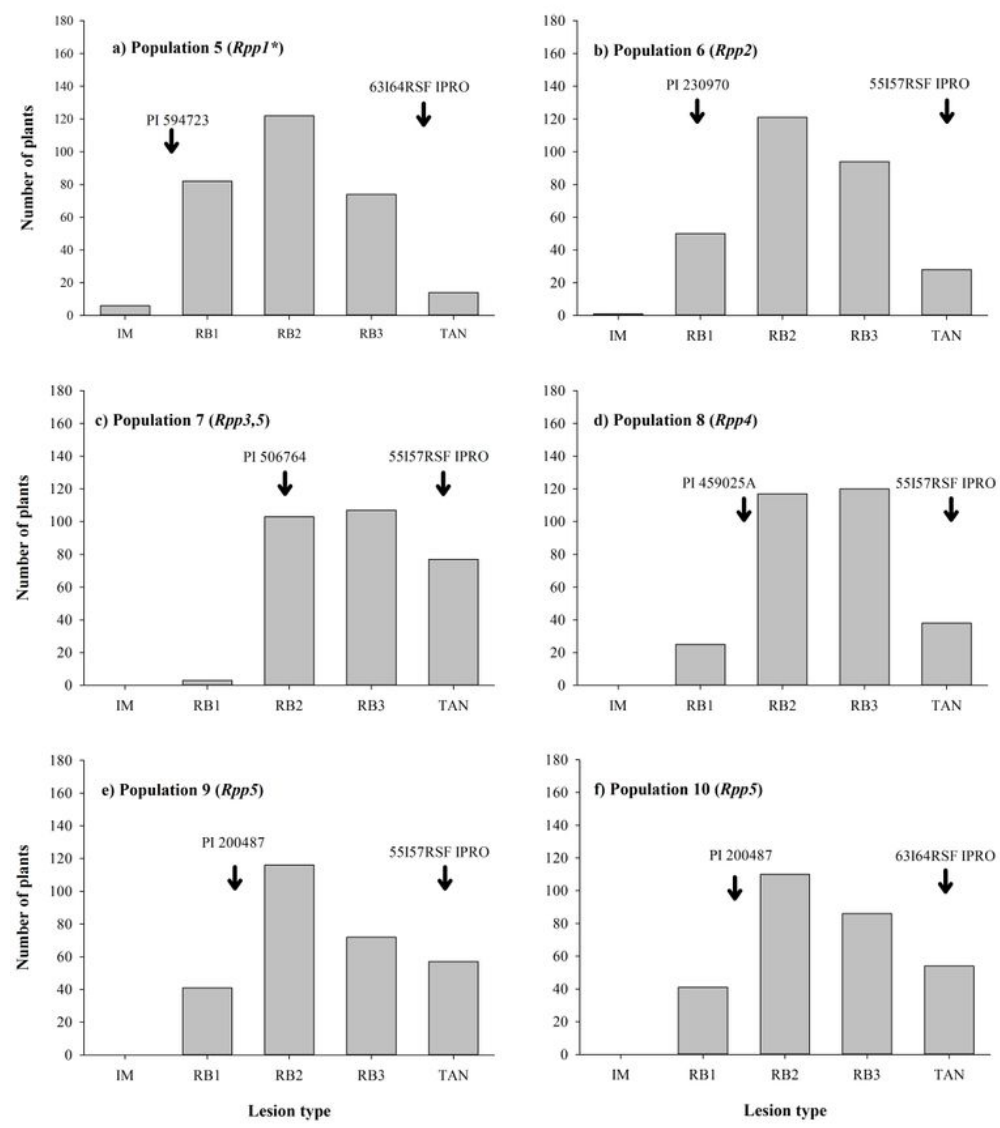

\section{Figure 3}

Frequency distributions of disease reaction to Asian soybean rust (ASR) in F2 soybean populations. a) Population 5 - Rpp1* (63I64RSF IPRO x PI 594723); b) Population 6 - Rpp2 (55I57RSF IPRO x PI 230970); c) Population 7 - Rpp3, 5 (55I57RSF IPRO x PI 506764); d) Population 8 - Rpp4 (55I57RSF IPRO x PI 459025A); e) Population 9 - Rpp5(55I57RSF IPRO x PI 200487); f) Population 10 - Rpp5 (63I64RSF IPRO x PI 200487) 


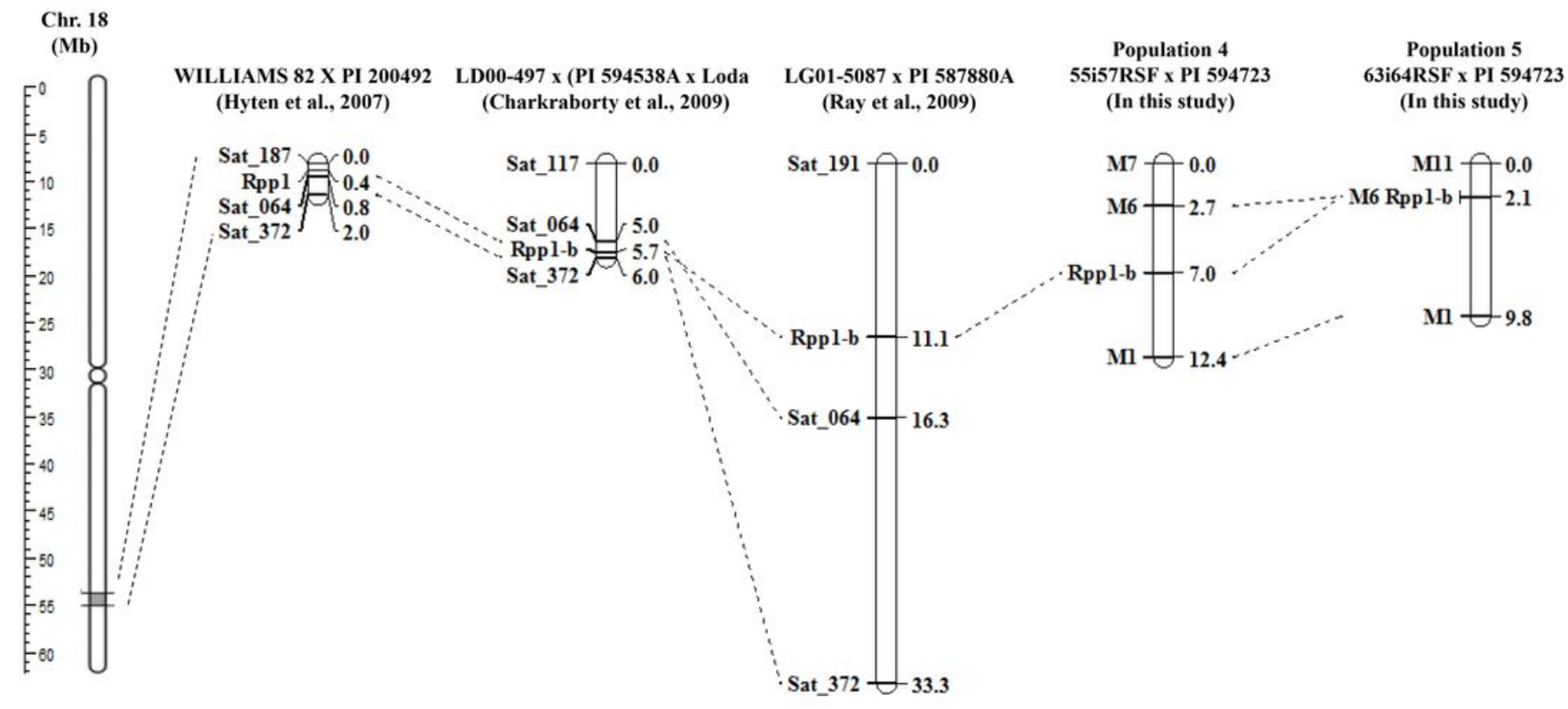

Figure 4

Compared linkage map location of Rpp1 conferring resistance to Asian soybean rust (ASR) on Chr 18 with the location of Rpp1 mapped in PI 200492 by (Hyten et al. 2007), Rpp1-b mapped in PI 594538A by (Chakraborty et al. 2009a), Rpp1-b mapped in PI 587880A by (Ray et al. 2009), and Rpp1-b mapped in this study in PI 594723. Map location of Rpp1-b in PI 594723 was based on the segregation of two trials composed of 69 and 298 F2 soybean plants for Population 4 - Rpp1* (55i57RSF x PI 594723) and Population 5 - Rpp1* (63i64RSF x PI 594723) 